\title{
Abacaxi 'pérola' produzido em floresta do Araguaia/PA: elaboração e perfil sensorial de produtos artesanais saborizados
}

O abacaxi da cultivar 'Pérola' é muito apreciado no mercado brasileiro interno devido à sua polpa ser suculenta e saborosa. $\mathrm{O}$ trabalho objetivou elaborar produtos artesanais (geleia e doce em massa) saborizados com flor de camomila e canela em pau, e avaliar suas características sensoriais. Para obtenção dos produtos foram elaboradas as seguintes formulações (F1: 30\% de polpa de abacaxi; 35\% de açúcar; $15 \%$ de xarope de glicose; $20 \%$ de albedo de maracujá; F2: $30 \%$ de polpa de abacaxi; $35 \%$ de açúcar; $15 \%$ de xarope de glicose; 19,95\% de albedo de maracujá; 0,05\% de flor de camomila desidratada e F3: 30\% de polpa de abacaxi; 35\% de açúcar; $15 \%$ de xarope de glicose; $19,9 \%$ de albedo de maracujá; $0,1 \%$ de canela em pau), as polpas concentradas e com/sem partículas foram acrescidas em função do teor de sólidos solúveis, a quantidade de açúcar suficiente para elevar a 65 (geleia) e $70^{\circ}$ Brix (doce em massa). As análises microbiológicas realizadas nas polpas e nos produtos artesanais elaborados foram fungos filamentosos e leveduras, Salmonella spp., Coliformes a 35 e a $45^{\circ} \mathrm{C}$ e Staphylococcus coagulase positiva. Para a avaliação sensorial foram realizados os testes de aceitabilidade para os seguintes parâmetros: aparência, aroma, textura, sabor e impressão global; assim como o índice de aceitação e a intenção de compra dos produtos. Os resultados das análises sensoriais dos produtos elaborados foram submetidos à análise de variância através do teste de Tukey a $5 \%$ de probabilidade. Os resultados verificados nas polpas de abacaxi e nos produtos elaborados, indicaram ausência de microrganismos para $25 \mathrm{~g}$ de amostra. Todos os parâmetros avaliados no teste de aceitação sensorial obtiveram notas médias entre 7 (gostei moderadamente) e 8 (gostei muito) indicando aceitação e intenção de compra dos produtos por parte dos provadores. Segundo os resultados observados na avaliação sensorial, os produtos podem se tornar uma opção tecnológica para os frutos de abacaxi devido a elevada aceitabilidade $(97,48$ a 98,45), assim como uma forma alternativa de renda para o pequeno produtor da região do Sudeste do Pará.

Palavras-chave: Camomila; Canela em pau; Aceitabilidade; Opção tecnológica.

\section{Pineapple 'pearl' produced in Araguaia/PA forest: preparation and sensory profile of flavored artisanal products}

\begin{abstract}
The pineapple of the cultivar 'Pearl' is very popular in the Brazilian domestic market due to its pulp being juicy and tasty. The work aimed to elaborate artisanal products (jelly and sweet pastry) flavored with chamomile flower and cinnamon stick, and to evaluate their sensory characteristics. To obtain the products, the following formulations were prepared (F1: 30\% pineapple pulp; 35\% sugar; $15 \%$ glucose syrup; $20 \%$ passion fruit albedo; F2: 30\% pineapple pulp; $35 \%$ sugar; $15 \%$ glucose syrup; $19.95 \%$ passion fruit albedo; $0.05 \%$ dehydrated chamomile flower and F3: $30 \%$ pineapple pulp; $35 \%$ sugar; $15 \%$ glucose syrup; $19.9 \%$ passion fruit albedo; $0.1 \%$ cinnamon stick), concentrated pulps and with / without particles were added depending on the content of soluble solids, the amount of sugar sufficient to raise 65 (jelly) and $70^{\circ}$ Brix (sweet pastry). The microbiological analyzes performed on the pulps and elaborated artisanal products were filamentous fungi and yeasts, Salmonella spp., Coliforms at 35 and $45^{\circ} \mathrm{C}$ and positive coagulase Staphylococcus. For sensory evaluation, acceptability tests were performed for the following parameters: appearance, aroma, texture, flavor and overall impression; as well as the acceptance index and the purchase intention of the products. The results of the sensorial analyzes of the elaborated products were submitted to the analysis of variance through the Tukey test at $5 \%$ probability. The results verified in the pineapple pulps and in the elaborated products, indicated absence of microorganisms for $25 \mathrm{~g}$ of sample. All parameters evaluated in the sensory acceptance test obtained average scores between 7 (I liked it moderately) and 8 (I liked it a lot), indicating acceptance and intention to buy the products by the tasters. According to the results observed in the sensory evaluation, the products can become a technological option for pineapple fruits due to the high acceptability (97.48 to 98.45), as well as an alternative form of income for the small producer in the Southeastern region of Pará.
\end{abstract}

Keywords: Chamomile; Cinnamon sticks; Acceptability; Technological option.

Topic: Tecnologia de Alimentos

Reviewed anonymously in the process of blind peer.
Received: 09/03/2020

Approved: 21/06/2020
Juliana Guimarães Rocha (iD

Universidade Federal Rural da Amazônia, Brasil

http://lattes.cnpq.br/1583032465194487

http://orcid.org/0000-0003-1786-5687

juguimaraes95@gmail.com

João Paixão dos Santos Neto

Instituto Nacional de Investigação de Portugal, Brasil

http://lattes.cnpq.br/2828947517814190

joaopaixaoneto@gmail.com

Igor Vinícius de Oliveira

Universidade Federal do Sul e Sudeste do Pará, Brasil

http://lattes.cnpq.br/1133025899150852

http://orcid.org/0000-0003-4218-5587

igor.oliveira@unifesspa.edu.br

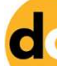

DOI: 10.6008/CBPC2237-9290.2020.002.0002

\author{
Fabio Israel Martins Carvalho (D) \\ Universidade Federal Rural da Amazônia, Brasil \\ http://lattes.cnpq.br/8221002637257793 \\ http://orcid.org/0000-0002-8995-2141 \\ fabioimc@yahoo.com.br
}

Priscilla Andrade Silva (ic

Universidade Federal Rural da Amazônia, Brasil

http://lattes.cnpq.br/7666887041806711

http://orcid.org/0000-0002-2774-3192

prisciandra@yahoo.com.br
Referencing this:

ROCHA, J. G.; SANTOS NETO, J. P.; OLIVEIRA, I. V.; CARVALHO, F. I. M.; SILVA, P. A.. Abacaxi 'pérola' produzido em floresta do Araguaia/PA: elaboração e perfil sensorial de produtos artesanais saborizados. Natural Resources, v.10, n.2, p.11-20, 2020. DOI: http://doi.org/10.6008/CBPC2237-9290.2020.002.0002 


\section{INTRODUÇÃO}

No Brasil, o abacaxizeiro (Ananas comosus L., Merrill) é explorado há muitas décadas, de forma predominante, em pequenas propriedades, com áreas médias inferiores a cinco hectares, onde se emprega na maioria das vezes a mão de obra familiar, com recursos próprios para implantação e manutenção da lavoura. Nos últimos anos, o agronegócio do abacaxi tem crescido significativamente, transformando-se no principal sustentáculo econômico de várias regiões em que a espécie é cultivada (CUNHA, 2007; LOBO et al., 2017).

A implantação de empreendimentos agroindustriais de pequeno e médio porte, como forma de promover a industrialização rural, a verticalização do setor primário e, consequentemente, a melhoria das condições socioeconômicas, é considerada uma das mais eficientes alternativas de desenvolvimento rural do país (FIGUEIREDO et al., 2010).

O abacaxi da cultivar 'Pérola' é muito apreciado no mercado brasileiro interno devido à sua polpa ser suculenta e saborosa, considerada insuperável para o consumo ao natural fazendo com que os frutos tenham grande potencial de comercialização internacional pois também são muito apreciados no Mercosul e na Europa (SOUTO et al., 2004).

$\mathrm{Na}$ atualidade, tem se buscado novos meios de aproveitamento do abacaxi, por ser uma fruta muito perecível, logo a indústria desempenha o papel de produzir polpas, sorvetes, iogurtes, doces, geleias e entre outros produtos, fazendo com que tenha no mercado uma diversidade de opções para o consumidor. 0 consumo e a comercialização de polpas vêm aumentando significativamente a cada ano, pois as pessoas tendem ao hábito de consumir sucos de frutas naturais em qualquer época do ano sem depender da sazonalidade (COSTA et al., 2013).

Os produtos artesanais mais difundidos pelos pequenos produtores são doces em massa e geleias, produtos simples e eficientes na conservação de frutas, características estas que os tornam muito apreciados pelos consumidores e elevam sua comercialização (SILVA, 1997). O doce em massa é obtido através do cozimento das frutas adicionando-se o açúcar até atingir a consistência desejada, podendo ser pastoso ou em massa de tal forma que possibilite o corte. Além do açúcar, outros ingredientes podem vir a ser acrescentados como a pectina e o ácido cítrico, que contribuem para a boa liga do doce (ANVISA, 2005). A geleia consiste numa estrutura firme, livre de partículas sólidas da fruta. É clara, brilhante, transparente, macia ao cortar, porém firme (TORREZAN, 1997).

A camomila (Matricharia chamomilla) é uma espécie originária do norte da Europa (zona dos Bálcãs), é cultivada em diversos países, entre eles o Brasil, é comum encontrá-la em terrenos baldios e jardins, lugares estes com tendência a disseminá-la rapidamente como planta invasora (ALONSO, 1998). A canela (Cinnamomum zeylanicum L.) pertence à família das Lauráceaes, que possui grande importância econômica na indústria alimentícia e cosmética. Nativa da Ásia e com distribuição na Índia, China, Sri Lanka e Austrália (SOUSA, 2011).

Conforme o supracitado, o trabalho objetivou a elaboração, bem como o estudo do perfil sensorial 
de produtos artesanais (geleia e doce em massa) saborizados com flor de camomila e canela em pau, obtidos a partir dos frutos de abacaxi da cultivar 'Pérola', cultivados em Floresta do Araguaia/PA.

\section{MATERIAIS E MÉTODOS}

\section{Obtenção da polpa de abacaxi e albedo de maracujá}

Os frutos de abacaxi cultivar Pérola foram coletados na propriedade rural Sítio Moreira localizada em Floresta do Araguaia/PA, com as seguintes coordenadas geográficas: $07^{\circ} 31^{\prime} 23^{\prime \prime}$ de latitude Sul e $47^{\circ} 39^{\prime} 04$, 9" de longitude a Oeste colhidos aos 18 meses após plantio. Os frutos selecionados foram lavados, sanitizados por imersão em solução com hipoclorito de sódio $(200 \mathrm{mg} / \mathrm{L})$ durante 15 minutos e novamente imersos em água por 15 minutos, separadamente. Em seguida, as amostras dos frutos foram manualmente separadas da polpa, batidas em liquidificador, peneiradas e embaladas em sacos plásticos de polietileno de $1 \mathrm{Kg}$ e congeladas a $-20^{\circ} \mathrm{C}$ para serem utilizada nas análises microbiológicas e no processamento dos produtos artesanais.

No processo de obtenção do albedo, os maracujás foram cortados com faca de aço inoxidável e as sementes e suco foram separados do albedo (parte branca da casca do maracujá), com auxílio de uma colher. O albedo foi retirado da película amarela (flavedo) do maracujá com auxílio de uma faca de aço-inox, submetendo ao processo de fervura (aproximadamente 20 minutos) por imersão em água, na proporção de $500 \mathrm{~g}$ de albedo e $1 \mathrm{~L}$ de água. Após a drenagem da água e o resfriamento, o albedo foi submetido ao processo de trituração em liquidificador, acrescido de água mineral na proporção de 1:1. Em seguida o gel foi envasado em recipientes de vidro de $250 \mathrm{~mL}$ e armazenadas sob refrigeração a $8^{\circ} \mathrm{C}$ até o momento da formulação das geleias e dos doces em massa.

\section{Elaboração dos produtos artesanais}

Os produtos elaborados, doce em massa e geleia de abacaxi foram desenvolvidos na Universidade Federal Rural da Amazônia, no Campus de Parauapebas Pará, localizada nas coordenadas geodésicas $49^{\circ} 51^{\prime} 19^{\prime \prime}$ W latitude, $06^{\circ} 12^{\prime} 58^{\prime \prime}$ S longitude, com altitude de $197 \mathrm{~m}$ com auxílio do GPS portátil (Modelo eTrex 10, Marca Garmin), assim como as análises microbiológicas e sensoriais. O período de realização do trabalho foi de março a julho de 2019. Para as formulações de doce em massa e geleia de abacaxi adequadas, foram realizados vários testes com diferentes concentrações de cada matéria-prima empregada. Para a elaboração dos produtos (doce em massa e geleia) foram utilizadas as seguintes matérias-primas: polpa de abacaxi, albedo de maracujá extraído dos frutos (Passiflora edulis), açúcar refinado, flor de camomila desidratada e canela em pau, comercializados nos supermercados de Parauapebas/PA.

Para as formulações dos doces em massa (F1: 30\% de polpa de fruta com partícula; 35\% de açúcar; 15\% de xarope de glicose; $20 \%$ de albedo de maracujá; F2: $30 \%$ de polpa de fruta com partícula; $35 \%$ de açúcar; $15 \%$ de xarope de glicose; $19,95 \%$ de albedo de maracujá; 0,05\% de flor de camomila desidratada e F3: $30 \%$ de polpa de fruta com partícula; $35 \%$ de açúcar; $15 \%$ de xarope de glicose; $19,9 \%$ de albedo de 
maracujá; 0,1\% de canela em pau), as polpas concentradas e com partículas foram acrescidas em função do teor de sólidos solúveis, segundo o cálculo, a quantidade de açúcar suficiente para elevar a $70^{\circ}$ Brix por balanço de massa (Equação 1): $\mathrm{Mp} x{ }^{\circ}$ Brixp $+\mathrm{Ma} \times{ }^{\circ}$ Brixa $=$ Mproduto $\mathrm{x}^{\circ}$ Brixproduto, onde: $\mathrm{Mp}=\mathrm{massa}$ de polpa; ${ }^{\circ}$ Brixp $={ }^{\circ}$ Brix da polpa; Ma= massa de açúcar; ${ }^{\circ}$ Brixa $={ }^{\circ}$ Brix do açúcar; $\mathrm{Mp}=$ massa do produto (geleia ou doce em massa); ${ }^{\circ}$ Brixp= massa do produto. Em seguida, apenas a polpa e as especiarias foram pasteurizadas $\left(90^{\circ} \mathrm{C}\right.$ por 30 segundos), e demais ingredientes foram acrescentados sob aquecimento ( $\mathrm{T}<$ $\left.100^{\circ} \mathrm{C}\right)$ até atingir o ponto de geleificação $\left(70^{\circ}\right.$ Brix). Os doces foram envasados imediatamente após cocção e mantidos sob temperatura ambiente até o momento das análises físico-químicas.

As formulações de geleias (F1: 30\% de polpa de fruta sem partícula, 35\% de açúcar, 15\% de xarope de glicose, $20 \%$ de albedo de maracujá; F2: 30\% de polpa de fruta sem partícula: 35\% de açúcar; 15\% de xarope de glicose; $19,95 \%$ de albedo de maracujá; 0,05\% de flor de camomila desidratada e F3: 30\% de polpa de fruta sem partícula; 35\% de açúcar; $15 \%$ de xarope de glicose; 19,9\% de albedo de maracujá; 0,1\% de canela em pau). Foram preparadas de maneira semelhante as dos doces em massa, com distinção apenas para o teor de sólidos solúveis, ajustado para $65^{\circ}$ Brix, seguido da etapa de filtração das partículas sólidas após a pasteurização. Foi calculado a quantidade de sacarose suficiente para elevar o teor de sólidos solúveis dos produtos elaborados: doce em massa e geleia, 70 e $65^{\circ}$ Brix respectivamente, utilizando-se o cálculo de balanço de massa, de acordo com a equação 1.

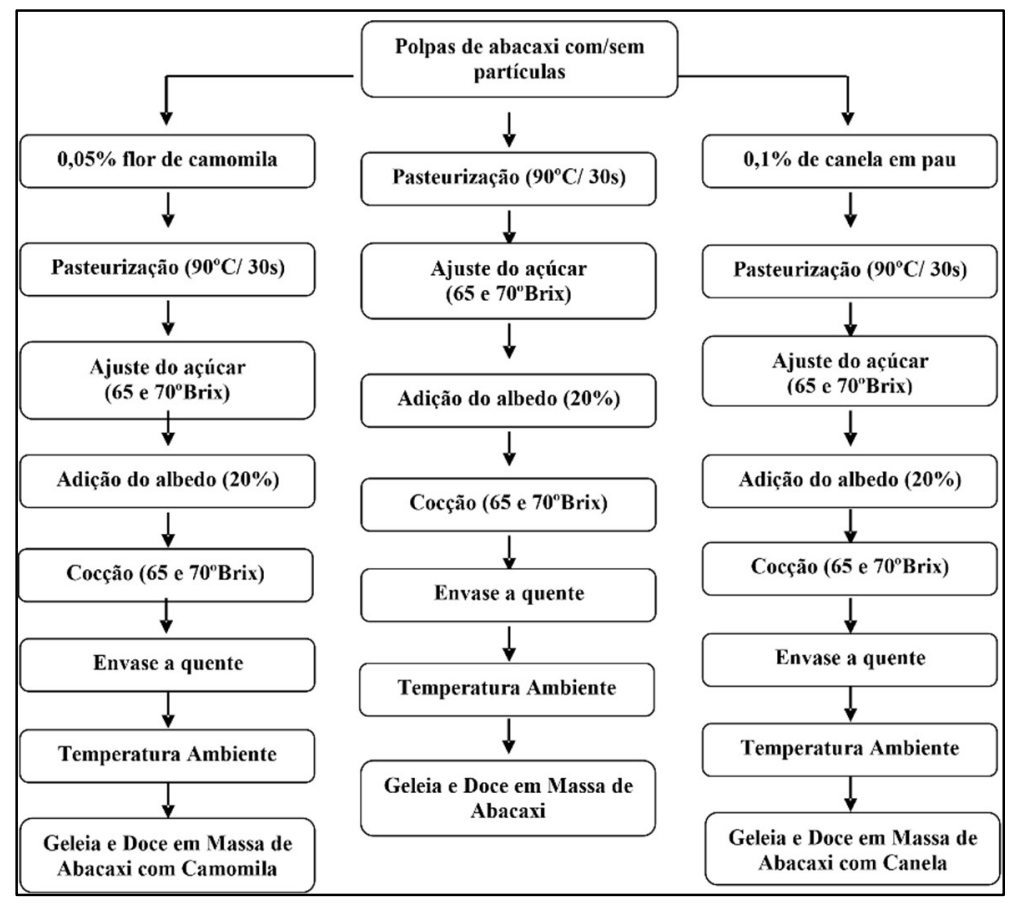

Figura 1: Fluxograma dos processos de produção dos produtos artesanais.

\section{Análises microbiológicas}

As análises microbiológicas foram realizadas (em triplicata) nas polpas de abacaxi e nos produtos artesanais elaborados, segundo recomendações e exigências da RDC n. 12 (BRASIL, 2001), para fungos filamentosos e leveduras, Salmonella spp., Coliformes a $35^{\circ} \mathrm{C}$ e a $45{ }^{\circ} \mathrm{C}$ e Staphylococcus coagulase positiva de acordo com Silva et al. (2001) 


\section{Análise sensorial}

A avaliação sensorial foi realizada na Universidade Federal Rural da Amazônia no Campus de Parauapebas, no mês de junho de 2019, por 100 provadores não treinados, selecionados aleatoriamente, de ambos os sexos, com faixa etária de 18 a 60 anos, pertencentes a comunidade acadêmica da UFRA. Para cada avaliador foi entregue uma ficha com o Termo de Consentimento Livre Esclarecido para Análise Sensorial, em seguida o mesmo recebeu aproximadamente 20 gramas das diferentes formulações de produtos artesanais (geleia e doce em massa), servidas em copinhos descartáveis (de $50 \mathrm{~mL}$ ) codificados com números de três dígitos aleatórios, um copo com água (de $150 \mathrm{~mL}$ ) e bolacha água e sal, sendo-lhe solicitado avaliar cada amostra, individualmente, quanto a aparência, aroma, textura, sabor e impressão global (modo geral do produto), utilizando uma ficha de avaliação com uma escala hedônica de nove pontos, ancorados em seus extremos nos termos gostei muitíssimo (9) e desgostei muitíssimo (1) (ABNT, 2014; DUTCOSKY, 2007; STONE et al., 1993).

Em seguida, foi solicitada a avaliação dos produtos quanto ao teste de intenção de compra, a fim de verificar se o produto seria bem comercializado ou não, com uma escala hedônica de 5 pontos, de acordo com o método de Dutcosky (2007). Após a análise, calculou-se o índice de aceitabilidade (IA) das formulações, de acordo com a seguinte fórmula: IA (\%) = A x 100 / B Em que, A = nota média obtida para o produto e $B=$ nota máxima dada ao produto (DUTCOSKY, 2007).

\section{Análise estatística dos dados}

Os resultados das análises sensoriais dos produtos artesanais (geleia e doce em massa) elaborados foram avaliados através das médias submetidas à análise de variância, e quando apresentaram diferenças foram comparadas pelo Teste de Tukey a 5\% de probabilidade, utilizando-se o software SAS ${ }^{\circledR}$ versão 9.4 (SAS INSTITUTE, 2013).

\section{RESULTADOS E DISCUSSÃO}

\section{Análises microbiológicas}

Os resultados verificados nas polpas de abacaxi e nos produtos elaborados (geleia e doce em massa), indicaram ausência de fungos filamentosos e leveduras, Salmonella spp., Coliformes 35 e a $45{ }^{\circ} \mathrm{C}$, Staphylococcus coagulase positiva, para $25 \mathrm{~g}$ de amostra. Portanto, de acordo com a resolução $\mathrm{n}^{\circ} 12$, de 2 de janeiro de 2001, as raízes e os produtos estão dentro dos padrões determinados pela Resolução RDC, de 12 de janeiro de 2001, da Agência Nacional de Vigilância Sanitária (ANVISA, 2001).

\section{Avaliação sensorial dos nais produzidos}

Através da Figura 2, pode-se visualizar o perfil dos provadores dos produtos artesanais (doce em massa e geleia de abacaxi), na qual $53 \%$ dos participantes eram do sexo feminino e $47 \%$ do sexo masculino. A faixa etária também pode ser observada na Figura 2, e a faixa de 20 a 40 anos esteve superior a todas as outras com $63 \%$, seguida de $34 \%$ da faixa de 18 a 20 anos e por último a faixa 40 a 60 anos, com 3\% do total 
dos provadores.

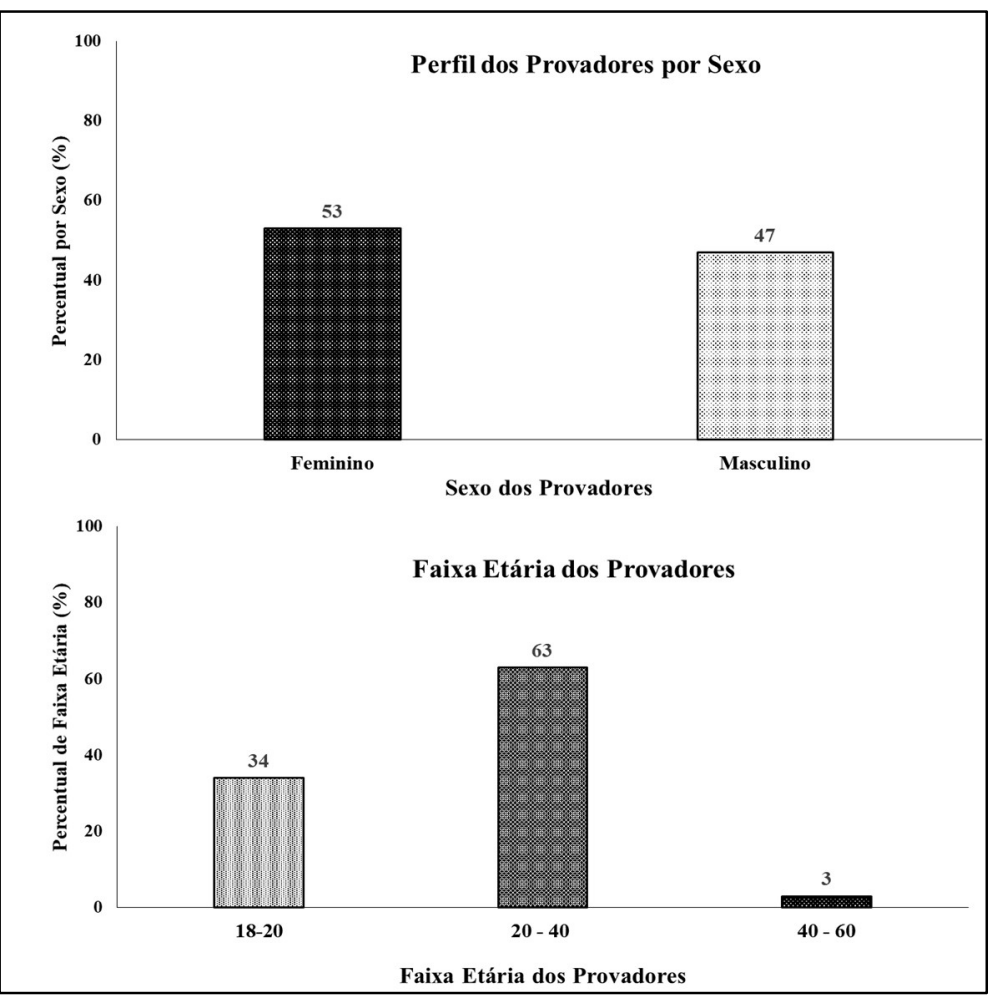

Figura 2: Perfil e faixa etária dos provadores.

Vieira et al. (2017) observaram em seu teste de aceitabilidade de geleia mista de casca de abacaxi e polpa de pêssego, que os consumidores entrevistados de ambos os sexos apresentaram a faixa etária entre 21 a 73 anos. E o maior percentual de consumidores encontrou-se na faixa etária entre 21 a 60 anos (79\%), seguido por aqueles entre 61 a 73 anos (21\%). Destes, $64 \%$ eram do sexo feminino e $36 \%$ do sexo masculino. Lima et al. (2017) em seu doce de abacaxi Pérola observaram uma faixa etária de provadores de 15 a 60 anos, sendo que $60 \%$ encontravam-se entre 15 a 30 anos, $25 \%$ encontravam-se entre 30 a 45 anos e $15 \%$ dos provadores de 45 a 60 anos. Os produtos foram analisados sensorialmente quanto à aparência, aroma, textura, sabor e impressão global. As médias para cada atributo analisado de doce em massa e geleia de abacaxi podem ser visualizados na Tabela 1.

Tabela 1: Avaliação Sensorial dos produtos elaborados (geleia e doce em massa).

\begin{tabular}{|c|c|c|c|c|c|c|}
\hline \multirow{2}{*}{\multicolumn{2}{|c|}{$\begin{array}{l}\text { Produto/ } \\
\text { Formulações }\end{array}$}} & \multicolumn{5}{|c|}{ Atributo (média \pm desvio padrão) } \\
\hline & & \multirow{2}{*}{$\begin{array}{l}\text { Aparência } \\
7,95 \pm 0,81^{a}\end{array}$} & \multirow{2}{*}{$\begin{array}{l}\text { Aroma } \\
7,82 \pm 1,51 \underline{a}\end{array}$} & \multirow{2}{*}{$\begin{array}{l}\text { Textura } \\
7,76 \pm 1,33 \text { a }\end{array}$} & \multirow{2}{*}{$\begin{array}{l}\text { Sabor } \\
8,06 \pm 1,28 \text { a }\end{array}$} & \multirow{2}{*}{$\begin{array}{l}\text { Impressão Global } \\
7,97 \pm 1,25 a\end{array}$} \\
\hline & DM & & & & & \\
\hline 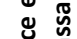 & DMCM & $7,18 \pm 1,77^{b}$ & $7,22 \pm 1,06^{b}$ & $7,40 \pm 1,03$ & $7,56 \pm 1,03^{b}$ & $7,48 \pm 0,95^{b}$ \\
\hline$\stackrel{\overbrace{}}{\mathrm{E}}$ & DMCN & $7,70 \pm 1,02 \underline{a}$ & $7,32 \pm 1,25^{\mathrm{ab}}$ & $7,80 \pm 0,95 \underline{a}$ & $7,70 \pm 1,09^{\mathrm{ab}}$ & $7,60 \pm 0,93^{\mathrm{ab}}$ \\
\hline & DMS & 0,4317 & 0,5102 & 0,4623 & 0,4667 & 0,4224 \\
\hline & F cálc. & 9,47 & 4,53 & 2,56 & 3,48 & 4,06 \\
\hline & $\mathrm{CV}$ & 11,97 & 14,45 & 12,75 & 12,67 & 11,60 \\
\hline \multirow{6}{*}{$\frac{\frac{\pi}{4}}{\mathbb{0}}$} & GA & $7,78 \pm 0,91 \mathfrak{a}$ & $7,70 \pm 1,07 \underline{a}$ & $7,58 \pm 0,95^{a}$ & $7,63 \pm 1,02^{a}$ & $7,61 \pm 0,95^{a}$ \\
\hline & GACM & $7,36 \pm 1,01 \mathrm{a}$ & $7,36 \pm 0,93 a$ & $7,08 \pm 0,94^{b}$ & $7,56 \pm 1,07 \underline{a}$ & $7,56 \pm 1,03 a$ \\
\hline & GACN & $7,40 \pm 0,73 a$ & $7,29 \pm 1,05$ & $7,54 \pm 0,97 \underline{a}$ & $7,40 \pm 0,99 \underline{a}$ & $7,44 \pm 0,93 \mathfrak{a}$ \\
\hline & DMS & 0,4208 & 0,4824 & 0,4526 & 0,4874 & 0,4595 \\
\hline & F cálc. & 3,40 & 2,32 & 4,23 & 0,66 & 0,39 \\
\hline & $\mathrm{CV}$ & 11,83 & 13,67 & 12,92 & 13,67 & 12,88 \\
\hline
\end{tabular}

DMS - Diferença mínima significativa; médias seguidas pela mesma letra na coluna não diferem estatisticamente entre si pelo teste de Tukey ao nível de $5 \%$ de probabilidade; ns - não significativo; * - significativo ao nível de 5\% de probabilidade. DM (Doce em massa de abacaxi); DMCM (Doce em massa de abacaxi com camomila); DMCN (Doce em massa com canela); GA (Geleia de abacaxi); GACM (Geleia de abacaxi com camomila); GACN (Geleia de abacaxi com canela). Os valores representam a média \pm desvio padrão de 100 provadores $(n=100)$. 
Os valores médios obtidos para os parâmetros avaliados, aparência, aroma, sabor e impressão global se diferiram $(p<0,05)$. Enquanto, a textura não obteve diferença significativa $(p>0,05)$ entre as três formulações de doce em massa (Tabela 1). Analisando os dados obtidos desta análise sensorial do doce em massa de abacaxi, verificou-se de acordo com a Tabela 1, quanto à aparência, todas as formulações foram bem aceitas, dentre estas, a amostra DM destacou-se pela maior aceitação que as demais $(7,95)$, a qual não continha adição de camomila e canela em sua formulação. Quanto a este atributo, Menezes (2008) encontrou valor de 7,39 em seu doce em massa de goiaba.

Quando avaliado o atributo aroma, observa-se que a amostra DM (Doce em massa de abacaxi) $(7,82)$ se sobressaiu melhor, apesar de todas as amostras alcançarem média acima de 7 , indicando na escala a aceitação 'gostei moderadamente' e 'gostei muito'. Valores estes superiores aos encontrados por Lima et al. (2012) em seu doce de corte de seriguela, a qual apresentou valor médio de 6,54 para o atributo aroma.

Observaram-se quanto ao parâmetro textura que a amostra com adição de canela obteve maior valor médio atribuído, em relação as outras apresentando 7,80 (DMCN - Doce em massa de abacaxi com canela)) e amostra de camomila menor (7,40). Lima et al. (2012) encontraram um valor médio de 7,36 em seu estudo com doce de corte de seriguela, valor este próximo aos das amostras analisadas.

Em relação ao atributo sabor, a amostra DM (Doce em massa de abacaxi) alcançou uma média de 8,06, o que representa na escala 'gostei muito', valor este superior as demais amostras, apesar de todas estarem acima da nota 7. Dias et al. (2011) encontraram um valor de 7,35 em seu doce em massa de casca de maracujá, valor este inferior ao observado para a amostra DM do presente trabalho.

O parâmetro impressão global indicou que a formulação DM (Doce em massa de abacaxi) com maior média $(7,97)$ sem adição de camomila e canela foi a preferida pelos consumidores. Na avaliação sensorial das geleias de abacaxi os parâmetros de aparência, aroma, sabor e impressão global não apresentaram diferenças significativas $(p>0,05)$ nas três formulações representadas na Tabela 1 . Enquanto os valores médios obtidos para textura se diferiram $(p<0,05)$ das demais amostras, a qual a GA obteve uma nota maior $(7,58)$ neste atributo.

Para o atributo aparência destacou-se a amostra GA (geleia de abacaxi) com média 7,78 e GACM (geleia de abacaxi com camomila) com nota menor $(7,36)$, o que pode ser atribuído a coloração mais clara do produto. Esses valores estão próximos aos averiguados por Damiani et al. (2009), os quais observaram no estudo de geleia de manga um valor médio de 7,99 para o atributo aparência.

Observa-se quanto ao aroma que todas as amostras de geleia obtiveram nota acima de 7,29 (GACN - Geleia de abacaxi com canela), assim GA (geleia de abacaxi) $(7,70)$ obteve grande aceitabilidade pelos provadores. O valor da amostra GACN (geleia de abacaxi com canela em pau) está próximo ao de Damiani et al. $(2009)(7,23)$ em seu estudo com geleia de manga.

Pode-se observar quanto à textura das amostras de geleia que os valores variaram de 7,08 (GACM Geleia de abacaxi com canela) a 7,58 (GA - Geleia de abacaxi). No trabalho de Lima et al. (2012), foram encontrados valores variando de 7,02 a 7,62 em sua geleia de seriguela, logo se assemelham as amostras de geleias de abacaxi em questão. 
Em relação ao sabor, a amostra GA (Geleia de abacaxi) apresentou uma média acima de 7,63 e a amostra GACN (Geleia de abacaxi com canela em pau) $(7,40)$ foi a que obteve valor menor em relação as demais. A autora Lainetti (2017) encontrou um valor médio de 7,90 em seu estudo sobre a elaboração de geleia com pimenta. No parâmetro impressão global a formulação GA (Geleia de abacaxi) com maior média $(7,61)$ sem adição de camomila e canela foi a preferida pelos consumidores.

Segundo Teixeira et al. (1987) para que um produto seja considerado como aceito, em termos de suas propriedades sensoriais, é necessário que obtenha um índice de aceitabilidade de, no mínimo, $70 \%$. Deste modo, todos os doces e geleias com suas diversas formulações obtiveram média acima de 7, no qual compreende entre 'gostei moderadamente' e 'gostei muito' pelos consumidores. Vale ressaltar que as amostra DM (Doce em massa de abacaxi) e GA (geleia de abacaxi) foram as que obtiveram destaque com valores acima da média $(7,0)$ para cada atributo avaliado.

Na Tabela 2, pode-se observar os valores médios do índice de aceitabilidade dos doces em massa e geleias de abacaxi. Os doces em massa obtiveram os valores de 97,48 a 98,16\%. Chim et al. (2017) em seu doce em massa light de pêssegos obtiveram 71,4\% de aceitabilidade. Segundo Dutcosky (1996), é necessário que o produto obtenha no mínimo 70 \% de aceitação para que possa ser viabilizada a sequência de testes para sua introdução no mercado.

Tabela 2: Índice de aceitação dos produtos artesanais de abacaxi com base no atributo impressão global.

\begin{tabular}{lll}
\hline \multirow{2}{*}{ Formulações } & \multicolumn{2}{l}{ Índice de Aceitabilidade (\%) } \\
\cline { 2 - 3 } & Doce em massa & Geleia \\
\hline F1 (produtos de abacaxi) & 98,16 & 98,45 \\
F2 (produtos de abacaxi com camomila) & 97,48 & 97,61 \\
F3 (produtos de abacaxi com canela) & 97,69 & 98,27 \\
\hline
\end{tabular}

F1: doce em massa e geleia de abacaxi puro; F2: doce em massa e geleia de abacaxi com camomila e F3: doce em massa e geleia de abacaxi com canela. Os valores representam o índice de aceitação calculado com base na nota atribuída pelos 100 provadores.

As geleias obtiveram valores de índice de aceitabilidade no intervalo de 97,61 a 98,45\%, o que demonstra um elevado índice de aceitabilidade. Valores estes próximos aos de Amaral et al. (2012), o qual obteve $98 \%$ de aprovação para a geleia de casca de maracujá e 92\% para a geleia de polpa de maracujá. Germano et al. (2017) em sua geleia mista de abacaxi com pimenta encontraram valores de 74,4 e 80,0\% de aceitabilidade entre os consumidores.

Em relação a intenção de compra, os doces em massa obtiveram grande aceitabilidade, no qual podese visualizar para o doce em massa de abacaxi (DM) que $24 \%$ certamente compraria, enquanto $17 \%$ possivelmente compraria (Figura 2). Para o doce em massa de abacaxi com camomila (DMCM) obteve-se os seguintes valores, $16 \%$ dos provadores afirmaram que certamente comprariam, enquanto $17 \%$ possivelmente comprariam o produto. Quanto ao doce em massa de abacaxi com canela (DMCN) $16 \%$ dos provadores alegaram que certamente comprariam, enquanto $20 \%$ possivelmente comprariam, e somente $4 \%$ possivelmente não comprariam o produto. Silva et al. (2014) verificaram que $12 \%$ dos julgadores certamente comprariam o doce de casca de maracujá e 34\% possivelmente comprariam o produto. 


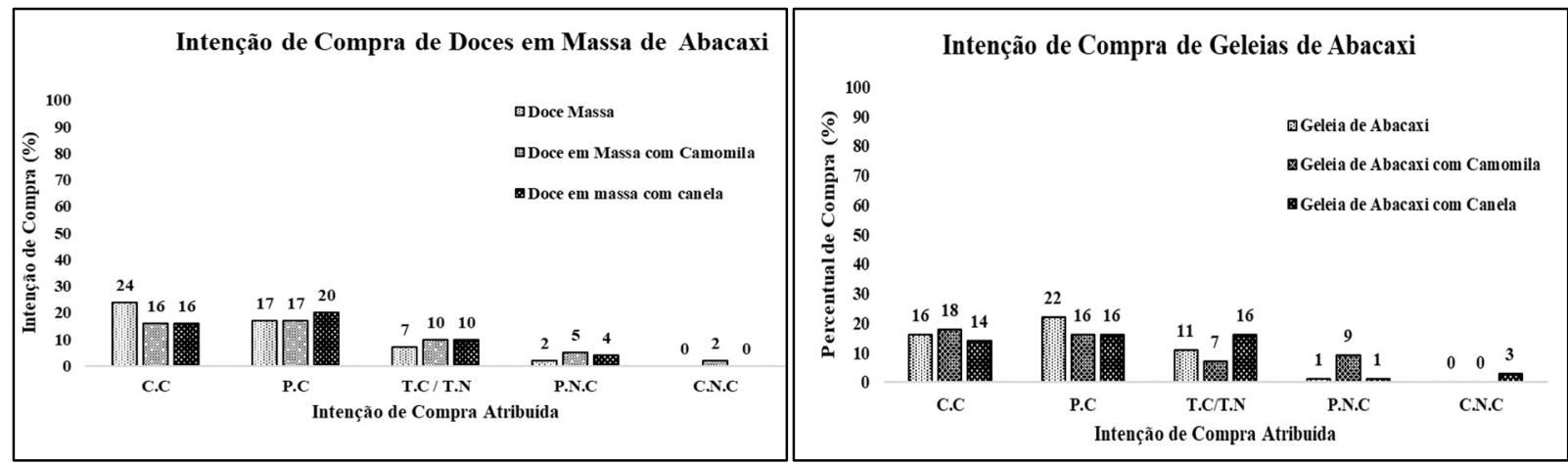

Figura 2: Intenção de compra para os produtos artesanais: Doces em Massa e Geleias .CC (Certamente Compraria), PC (Possivelmente Compraria), TC (Talvez Compraria), PNC (Possivelmente Não Compraria) e CNC (Certamente Não Compraria).

A geleia apresentou grande aceitabilidade pelos provadores como pode ser observado na Figura 2. A geleia de abacaxi (GA) obteve $16 \%$ de intenção de compra, o que representa na escala certamente compraria, enquanto $22 \%$ possivelmente compraria o produto. Para geleia de abacaxi com camomila (GACM), apresentou $18 \%$ de intenção em certamente compraria, 16\% possivelmente compraria. Já para a geleia de abacaxi com canela (GACN), $14 \%$ dos provadores afirmaram que certamente comprariam, enquanto $16 \%$ possivelmente comprariam o produto caso estivesse a venda. Lainetti (2017) observou em seu trabalho de geleia de abacaxi com pimenta, $23,8 \%$ dos provadores certamente comprariam a geleia, enquanto $42,7 \%$ possivelmente comprariam o produto.

\section{CONCLUSÕES}

As análises microbiológicas realizadas nas polpas e nos produtos artesanais (geleia e doce em massa) obtidos a partir do abacaxi 'Perola' estiveram dentro dos padrões exigidos pela legislação vigente, refletindo, assim, a qualidade higiênica do processamento. Quanto aos parâmetros avaliados no teste de aceitação sensorial (aparência, aroma, textura, sabor e impressão global) dos produtos artesanais de abacaxi, com camomila e canela todos obtiveram notas médias entre 7 (gostei moderadamente) e 8 (gostei muito), indicando aceitação acima de $90 \%$ dos produtos por parte dos provadores mesmo com a adição de camomila e canela. Com destaque para o atributo sabor (nota 8,06) do doce em massa de abacaxi sem especiarias (DM), o qual recebeu maior nota atribuída pelos provadores.

Diante o exposto, os produtos artesanais elaborados como doce em massa e geleia de abacaxi saborizados com camomila e canela em pau apresentaram elevada aceitabilidade sensorial e intenção de compra, logo surgem como uma nova proposta para a cadeia produtiva do abacaxi, bem como uma alternativa de renda para o pequeno produtor da região Sudeste do Pará.

\section{REFERÊNCIAS}

ABNT. Associação Brasileira de Normas Técnicas. NBR ISO 5492:2014: Análise sensorial dos alimentos e bebidas: terminologia. São Paulo: ABNT, 2014.

ALONSO, J. R. M.. Tratado de fitomedicina: bases clínicas y farmacológicas. Buenos Aires: ISIS EDITORIAL, 1998.
AMARAL, D. A.; PEREIRA, M. L. S.; FERREIRA, C. C.; GREGÓRIO, E. L.. Análise sensorial de geleia de polpa e de casca de maracujá. HU Revista, Juiz de Fora, v.38, n.3-4, p.181-186, 2012.

ANVISA. Agência Nacional de Vigilância Sanitária. Resolução da Diretoria Colegiada, RDC no 272, de 22 de setembro de 
2005. Aprova o regulamento técnico para produtos de vegetais, produtos de frutas e cogumelos comestíveis. Brasília: DOU, 2005.

ANVISA. Agência Nacional de Vigilância Sanitária. Resolução RDC $\mathbf{n} .12$ de 02 de janeiro de 2001. Dispõe sobre o regulamento técnico sobre padrões microbiológicos para alimentos. Brasília: DOU, 2001.

CHIM, J. F.; ZAMBIAZI, R. C.; RODRIGUES, R. S.. Caracterização físico-química e sensorial de doce de pêssegos convencional e light. Revista Brasileira de Produtos Agroindustriais, Campina Grande, v.19, n.1, p.4147, 2017.

COSTA, D. O. D.; CARDOSO, G. R.; SILVA, G. M. V. D.. A evolução do setor produtivo e comercialização de polpa de fruta no brejo paraibano: estudo de caso na coaprades. In: ASSOCIAÇÃO BRASILEIRA DE ENGENHARIA DE PRODUÇÃO. Anais. Salvador: ABEPRO, 2013. p.16.

CUNHA, G. A. P.. Equipe técnica do abacaxi comemora 30 anos de atividades e realizações. Cruz das Almas: Embrapa Mandioca e Fruticultura Tropical, 2007.

DAMIANI, C.; BOAS, E. V. B. V.; SOARES JUNIOR, M. S.; CALIARI, M.; PAULA, M. L.; ASQUIERI, E. R.. Avaliação química de geleias de manga formuladas com diferentes níveis de cascas em substituição à polpa. Ciência e Agrotecnologia, Lavras, v.33, n.1, p.177-184, 2009. DOI: https://doi.org/10.1590/S1413-70542009000100025

DIAS, M. V.; FIGUEIREDO, L. P.; VALENTE, W. A.; FERRUA, F. Q.; PEREIRA, P. A. P.; PEREIRA, A. G. T.; BORGES, S. V.; CLEMENTE, P. R.. Estudo de variáveis de processamento para produção de doce em massa da casca do maracujá (Passiflora edulis $f$. flavicarpa). Ciência e Tecnologia de Alimentos, v.31, n.1, p.65-71, 2011. DOI: https://doi.org/10.1590/S0101-20612011000100008

DUTCOSKY, S. D.. Análise sensorial de alimentos. Curitiba: Champagnat, 1996.

DUTCOSKY, S. D.. Análise Sensorial de Alimentos. 2. Ed. Curitiba: Champagnat, 2007.

FIGUEIREDO, A. F. R.; FIGUEIRÊDO, V. R.. Treinamento agroindustrial de pequenos produtores do Sul da Bahia. Extension: R. Eletr. de Extensão, Florianópolis, v.7, n.10, p.150-157, 2010.

GERMANO, L. D.; NACHTIGALL, A. M.; BOAS, B. M. V.. Elaboração e avaliação de geleia mista de abacaxi com pimenta. Tecnologia \& Ciência Agropecuária, João Pessoa, v.11, n.6, p.107-111, 2017.

LAINETTI, A. M. S.. Elaboração de geleia de abacaxi com pimenta. Monografia (Bacharelado em Tecnologia de Alimentos) - Universidade Tecnológica Federal do Paraná, Londrina, 2017.

LIMA, I. C. G. S.; MELEIRO, C. H. A.. Desenvolvimento, avaliação físico-química e sensorial de geleia e doce de corte de seriguela (Spondias purpúrea L.) visando o crescimento da cadeia produtiva do fruto. Boletim do Centro de Pesquisa e Processamento de Alimentos, v.30, p.221-232, 2012. DOI: http://dx.doi.org/10.5380/cep.v30i2.30495

LIMA, P.C; SOUZA, B. S.; SANTINI, A. T.; OLIVEIRA, D. C.. Aproveitamento agroindustrial de resíduos provenientes do abacaxi 'pérola' minimamente processado. Holos, Natal, v.2, p.122, 2017. DOI: http://doi.org/10.15628/holos.2017.5238

LOBO, M. G.; YAHIA, E.. Biology and Postharvest Physiology of Pineapple. Hoboken: John Wiley \& Sons Ltd., 2017.

SAS INSTITUTE. SAS for Windows, versão 9.4 SAS ${ }^{\circledR}$ : SAS User guide. Carry, 2013.

SILVA, E.S.; SANTOS, E. R.; ROSA, J.; TOSTE, F. C.; SOUZA, G. G.; NOGUEIRA, R.; NASCIMENTO, K. O.. Aproveitamento integral de alimentos: avaliação físico-química e sensorial de um doce obtido a partir de cascas do maracujá amarelo (Passiflora edulis f. Flavicarpa). Revista Augustus, v.19, p.4460, 2014. DOI:

http://dx.doi.org/10.15202/10.15202.2014v19n38p44

SILVA, F. T.. Manual de produção artesanal de doce em massa. Rio de Janeiro: EMBRAPA, 1997.

SILVA, N.; JUNQUEIRA, V. C. A.; SILVEIRA, N. F. A.. Manual de métodos de análise microbiológica de alimentos. 2 ed. São Paulo: Varela, 2001.

SOUSA, P. R. S.. Avaliação antifúngica do óleo essencial de Cinnamomum zeylanicum Blume como promotor do controle do gênero Penicillium do ar ambiental em sistema industrial alimentar. Tese (Doutorado em Produtos Naturais e Sintéticos Bioativos) - Universidade Federal da Paraíba, João Pessoa, 2011.

SOUTO, R. F.; DURIGAN, J. F.; SOUZA, B. S.; DONADON, J.; MENEGUCCI, J. L. P.. Conservação pós-colheita de abacaxi 'Pérola' colhido no estádio de maturação 'pintado' associando-se refrigeração e atmosfera modificada. Revista Brasileira de Fruticultura, v.26, p.24-28, 2004. DOI: http://doi.org/10.1590/S0100-29452004000100008

STONE, H. S.; SIDEL, J. L.. Sensory Evaluation Practies. 2 ed. San Diego: Academic Press, 1993.

TEIXEIRA, E.; MEINERT, E.; BARBETTA, P. A.. Análise sensorial de alimentos. Florianópolis: Universidade Federal de Santa Catarina, 1987.

TORREZAN, R.. Preparo caseiro de geleias. Rio de Janeiro: EMBRAPA, 1997.

VIEIRA, E. C. S.; SILVA, E. P.; MENDONÇA, C. C.; SOUSA, G. M.; BECKER, F. S.; DAMIANI, C.. Aceitabilidade e características físico-químicas de geleia mista de casca de abacaxi e polpa de pêssego. Científica, Jaboticabal, v.45, p.115-122, 2017. DOI: http://dx.doi.org/10.15361/19845529.2017v45n2p115-122

A CBPC - Companhia Brasileira de Produção Científica (CNPJ: 11.221.422/0001-03) detém os direitos materiais desta publicação. Os direitos referem-se à publicação do trabalho em qualquer parte do mundo, incluindo os direitos às renovações, expansões e disseminações da contribuição, bem como outros direitos subsidiários. Todos os trabalhos publicados eletronicamente poderão posteriormente ser publicados em coletâneas impressas sob coordenação da Sustenere Publishing, da Companhia Brasileira de Produção Científica e seus parceiros autorizados. Os (as) autores (as) preservam os direitos autorais, mas não têm permissão para a publicação da contribuição em outro meio, impresso ou digital, em português ou em tradução. 